\title{
Role of Yoga and Meditation In The Empowerment of Women ; an Ethical Perspective
}

\author{
Dr. Rekha Ojha \\ Dept. of Philosophy Visva-Bharati University Santiniketan, West Bengal
}

\begin{abstract}
Role of Yoga and Meditation in the Empowerment of Women Today, many people are taking up Yoga techniques for physical exercise, and most don't know the history of yoga. They believe there is nothing wrong with implementing this form of exercise into their daily regiment to promote a more healthy body. However, the practice of yoga is much more then a system of physical exercise to health. Yoga is more a path of spiritual growth. The focus of this paper will be highlight power of meditation which can empower women, it will also bring up the issue of how we perceive our sexuality and our gender characteristics, and how their does and does not affect our true spiritual ideality. The paper will give more insight into the gender biases prevent in the society and also focus on the power of meditation in empowering women.
\end{abstract}

Keywords: Gender, women, sexuality, spirituality, meditation, empowerment. Role of yoga in the empowerment of women: An ethical perspective

\section{HISTORY OF YOGA}

I would like to begin the paper with a simple quotation given by Buddha, "The secret of health for both mind and body is not to mourn for the past, worry about the future or anticipate troubles but to live in the present moment wisely and earnestly. In India, yoga was the name of one of the highly regarded six schools of Indian Philosophy, which emerged from the Vedic civilization. Yoga has its origins in the search for the ultimat truth and reality; in the questions about the meaning and process of life; in the quest for contentment and well being. During pre Vedic period (before 3000 B.C approx) archeologists discovered status and paintings of figures representing what we see as Shiva, in various meditation and asana poses. Yoga is ageless time eternal holds secrets we are tapping into with our breath, body and passion. During Vedic period (around 2000BC) the Aryans, a group for Indo-European travelers settle in the heart of the Indus River Valley region mixing with the local inhabitants. Both groups share their culture and religion : belief in the power of Nature hold their imagination and hearts and the beginning of the practice of Yoga and Hinduism being (the term Hindu is actually beaten from other accounts of the Indus River Valley people, calling them first Indus, later to be called Hindu, so Hinduism is actually the practice of the Vedas rather than a specific religion). Even in the earliest hymns and prayers it is evident that the people believed in the Divine and that "Truth is One". The sages, much like the prophets in the Middle East, heard divine teaching and illuminations directly from God on the Nature and Way of being. These are the Vedas, first heard in deep meditation and passed on to students (shruti text that which is heard). The Vedas were the description of direct experience of God and the many way to form a relationship through prayer, ritual, song etc. Over time, these lessons were forgotton and students began writing them down as they were heard from these session came the Vedanta, lit, end of knowledge (anta=end, Veda=Truth), in the form of the Upanishad. These poems contain the knowledge of God, the experience of the Divine. However, because the mind is so dull God ego-centered, even the most diligent and still student had difficulty understanding these teaching, so the Brahma sutras were written. And yet again, people could not grap the infinite with their limited thinking and so the Mahabharata was written to illustrate these Vedic teachings. And from the Mahabharata came the Gita, or "The song of God", one of the most beautiful and illustrative stories of devotion and spiritual growth in the history of scripture. Here we first lean about the distinct path of Yoga and our responsibility as students of Yogic way. The Gita was the instrumental text that inspired Gandhi's vision and service and is sill read today by devoted student of Yoga.

Patanjali's Yoga Sutra (estimated around 600 BC) No definite date has been arrived at for Patanjali. Some scholars have identified him with the Sanskrit grammarian of the same name, who lived about 300 BC. But there is not proof that he was the same person. He certainly came after the Upanishads of early Buddhism, and probably also often Bhagavad Gita. That work widely popularized Yoga, but makes no mention of Patanjalii, nor of the most celebrated parts of the Sutras, the eight limbs of Yoga and the idea of Samyama., The Bhagavad Gita was concerned with Karma Yoga, Jnan and Bhakti Yoga. Patanjali's Yoga is really raja yoga, the yoga of mental processes, of mind and will power. The sutras are divided inot 4 chapter or pada, the fist chapter, Samadhi pada, describe the stages, obstacles and theory of Samdhi, the second chapter Sudhana Pada, describes yoga practice, beginning with a definition of Kriya yoga, which is the model of all of the modern 
hatha practices. The third chapter Vibhuti Pada, describe the benefits of deep practice, including supernatural gifts, and the fourth chapter, Kaivalya Pada,deals with the metaphysical aspect of yoga.

\section{Post Vedic Modern Yoga:}

This age is also known as the birth of Hatha yoga. This sutra were supposedly written around the time of the Buddha, a time in our spiritual history where the mind we used as a took for observing the truth of Nature and where the teachings dissected us to sit meditation for long periods of time to soften the mind and open the Heart to the ultimate reality of our unity with Nature and that the mind causes our suffering and limits us on our search for truth. The Buddha, along with other Rajas yogis, taught that first we control ourselves with discipline and self control before going deeper into other practices. Buddhism was spreading through India and many monks were forsaking their physical practice for the more settled one of meditation. However as most humans are not capable of using the mind to understand and control the mind, many students were lost in their own neurosis and complications. Matsyendranth, a yogi sage, fraught the practice of Yoga back to the physical and with his school of Nath focused the practice back on the body. He thought contorl the mind was too difficult and that unless the body was clean balanced and pure the mind would not settle and Samadhi could not be achieved. So the asanas became a larger focus in the practice around 200 AD Swami Swatmarama wrote the Hatha Yoga Pradipika, the quintessential guide to hatha practice, The Hatha Yoga Pradipka is a manual for doing just that using asanam, pranayama, mudra, bandhas, and shakkarmas. The body is first made pure allowing the mind on once these first practices and mastered.

From this perspective and using this text many began teaching asanas as central to the practice and from this shift comes the modern approach to teaching yoga.

\section{Modern Yoga Lineages:}

Although Hatha Yoga fits into the greater path of Raja Yoga and can be traced back hundred of years, most of the modern practices, at least in the West are based on several teachers' understanding of Yoga. Srikrishnamacharya and Sri Sivanda are instrumental for transmitting Yoga throughout he world, making yoga a household name and practice. From Krishnamacharya came Desikachar and his Vinny Yoga, Bks Yyengar and Pattabhi Jois, whose intense Astanga Yoga is widely practiced among type A's and gymnasts. Sivannada, whose style of yoga that includes service and love has change many lives in the west and has given us Vishnu Devanda, who started the International Sivanda Centre, Satchindanada of Intergral Yoga that teaches Raja Yoga and Swami Satyanada whose Bihar yoga focuses mainly on traditional Hatha Yoga.

And from each of there teachers comes the more familiar names like Bikram, Lee, Griley, Shaw and other Western Yogis that have helped create a space for disciplining the body and stilling the mind through their teaching. However, we should never forget and sever the roots of yoga without a strong understanding and gratitude for the teaching and sages of the past, whose knowledge is timeless and carries the seeds of peace, our own practice could be a shallow interpretation of our True Nature. We should practice knowing that Union and Transformation are possible and within our grasp and that limiting our Yoga practice to the physical is limiting and partial. A whole, balanced practice and understanding of our yoga depends on the realization that yoga is our whole lives, the way we breath, what we eat, how we talk, the people we associate with, our service to people in need, our disciplined asana and pranayama practices and the love and devotion to God in each moment.

\section{Yogini:}

Yogini is the complete form source word of the masculine yoga. In other word yogin is used for women yogis. Far from being merely a tag to all things yogi. "Yogini, represents both a female master practitioner of yoga, and formal term of respect for a category of modern female spiritual teachers (in Hinduism and Buddhism) in eastern country such as India, Nepal and Tibet. In the Hindu tradition, mother is first guru (teacher) and in the yoga tradition, proper respect of yoginis is a necessary part of the path of liberation. A yogini is the sacred feminine force made incarnate : the goddesses of mythology (Kali, Durga, Lakshmi, etc) as well as ordinary human women who is enlightened, both having exuberant passion, spiritual power and deep insight, capable of giving birth to saints, peacemakers, and yogis. The point which I would like to focus here is that the human women were recognized in the society mostly if they are capable of giving birth to saints, peacemakers and yogis1. So we can say that gender bias is deep rooted from the beginning of the culture. But this was not only the case, in the book passionate enlightenment. Women in Tantric Buddhism, written by Miranda Shaw. She writes that a large number of women like Dombiyagine, Sahjayagicinta, Lakshmikara, Mekhala, Konkhala Gangadhara, Siddharajni, and other, were respected yoginis and advanced seekers on the path to enlightenment. We also have the example of married tantric practitioners who require to devote significant time to retreat and spiritual practice. Ngagma (Buddhist female practisner) are particularly known for performing birth rituals, wedding, funerals, divinations, and pacification of spiritual disruptions. Some 
nagagmas are comparable in practice to the Mahasidda yoginis of India Buddhism. The two term 'yogi' and and 'yogini' are still used today but the word yogi is most generically used to refer to both male and female practitioners of yoga and related meditative practices in Buddhism, Jainism, Toism etc. In a wider and general context a Yogini is a human women who through the practice of yoga, may passes spiritual power, including the ability to trancened the Normal aging process, via internalization of the reproductive power known as urdhvaretas (upward refinement of the seed force) and even death, attaining divya sharira (immortal divine body). Through the leaders of the modern yoga asana meditation tradition have often been made, the vast majority of modern practioners are female ${ }^{2}$, including many who have attained mastery via steadfast awareness through the shakti sensations of menses, fertility, childbirth, and breast feeding. In the shakta branch of Hinduism, creation myths pace the divine feminine at their centre, looking the tantric view that the nature of the cosmos (Macrocosm) is reflected in the human body (or Microcosm), and it is the Female when gestates and give birth to new life." Only the female can awaken the muladhara chakra (the seat of the Kudaline-Skati) via fertility and sexuality. ${ }^{3}$ Yogini may indicate an advanced yoga practitioner who is one who is a female who is an associate or attendant of Durga, a fierce aspect of the Divine feminine, who slays illusion and delusion through insight and liberation. There are many stories which really shows the inferor position of yogins for eg about Indra, the king of the Gods. The Narasimha Purana has the story of Brahmins wife, Savitri by name who is believed to attained supernatural power and wisdom by devoutly serving her husband. There are also popular puranic stories showing idealized love in married life are those of Sati and Uma ( a great yogins) who though much more divine that human, have been respected very highly and looked upon as ideals in all ages, are also believed to be for their strength of character and selfless, love for her husband. This was not the story of that age but also in the present age as we watch the T.V serials where women are potrate as sita we always admire the character but when the other women character is raising their voice we crititise that character. So to say that the society remains the same for ancient yogins or for modern women human being will not be wrong.

\section{Gender bias in society:}

Every human being has masculine and feminine traits in them. The difference between males and females is only a matter of some glands. Every spiritual person needs to recognize the universal power that universal power that pervades our existence. The role of male and female tantric is the same to break our shackles, that keeps us bound to transient body and the world. Our spiritual longing is the same. There has never been a absolute standard definition of what is to be make or female. There are may culture around the world which have evolved very ridgid definitions of what is male and female, but in recent history these definitions have became more loose and less confusing, still, generally, men are thought to be more aggressive, intellectual, competitive while women are thought to be intuitive, passive and cooperative. Gendar is social and consist of social expectation and assumptions about what behaviours and traits are appropriate for male and female individuals. For example it is commonly expected that males will relish confrontation while females will try to avoid it. It also consist of psychological traits, and the understanding of themselves, that individuals tend to develop under the influence of these social expectations. For instance, male often do come to relish confrontation than females. If one satisfies social expectations about what is appropriate for female (or male) individuals, than one is feminine (or masculine). So we can also say that gender consist of social ideas and expectation about what feminity and masculinity consist in or about what traits someone must display in order to count as feminine and masculine. These ideals about feminity and masculinity are organized by a higher level expectation that feminine and masculine behavior and traits are appropriate, respectively, for members of the female and male sex. There is a higher level expectation that females should be feminine makes masculine.

Gender differences are reflected in roles, responsibilities, access to resources, constraints, opportunities, needs, perceptive views etc held by both men and women gender bias refers to action against women or men based on the perception that the other is not equal and does not have the same rights.

Women are brought up to feel that they are inferior to men. In the course of Indian history from prehistoric to modern and contemporary times there ware district stages of the rise fall in the status and role found in a certain period and in a particular place / province has expressed opposite views about the worth nature and importance of women. According to one school, a woman is the best gift of God to man. She brings prosperity respected, and is called Lakshmi, the goddess of wealth and prosperity. The second school of thought holds the views that the best way to reach God is to avoid women ${ }^{4}$. sage Agastya says "Women combine the fickleness of the lighting, the sharpness of a weapon and the softness of the eagle. ${ }^{5}$ : The status enjoyed by the Indian women cannot easily be assessed. While the ideal was worshiped the real was neglected. Carmack assets "Traditional India has always accorded women a high place indeed equallity. ${ }^{6}$ Gorwaney also observes that "Ideally, women were accepted as a living force in society, the embodiment of Shakti and a symbol of purity, religiousness,spirituality and sacrifice7.If we survey the position of women in modern India it will draws us to a close, we realize all the more that to ensure a permanent and true emancipation of women, one must recognize the dignity of human life. Mental slavery is more difficult to remedy that political slavery, which at the worst is 
an external appendage. Woman must grow conscious of their own deserts and usefulness. Women with a mission in life should be given the opportunity to develop their particular abilities in their own way, and thus dedicate their live in her own way. The most serious disease of the present sophisticated generation of the world is that they have forgotten to respect life and instead of loving its goodness, despite its weeknesses. The outcome of each a mental attitude is its uninspired art and literature and its total lack of faith in the purpose of all life. India, which has scaled the heights of glory, and plumbed the depth of misery, must not let her women plung into this pitfall of hopelessness. Those who are waking from sleep expect the daylight, not the darkness. So let it be in India

\section{Power of Meditation in Empowering Women}

In reality our true identity exists beyond our gender, our gender is only a fractional past of our psyche. Our true identity is not dependent on our biological gender, or our sexual orientation. Consider Swami Inanesvara Bharati's poem, the secret of Shiva and Shakti, in which he describes the unity of masculine (Shiva) and feminine (Shakti) energies :

Siva and Shaki are one and the same.

There is no place that he is not.

There is no place she is not

They are one and the same.

Although the poem employs gender specific language it emphasizes that the he and she are one. Bharati's verses reflect the non-dualistic philosophies of Vedanta, Yoga and Tantra. The common thread that binds us all men and women alike is known by different names in each tradition. Patanjali calles it Purusha, Pure conciousness. In Tanta, it is dubbed infinite union of shiva and shakti. In the Upanishad, it is described as Atma, the centre o consciousness or the essence of Brahman, the absolute. Although there three traditions use different language to describe the non dual nature $\mathrm{f}$ reality, they all suggest a unifying essence at the core of every hunch being. If we look at sex (in the biological sense) through the lense of non-dualism, gender roles of society appear inconsequential. Despite differences in our physical bodies, there is an understanding that we all ultimately share the exact same energetic potential. Our sexual qualities are a part of us, they do not define us.

In nature, the male and female sexes where developed by means of evolution, because the splitting of genetic material into too separate genders was the most efficient way to transfer genetic diversity into the future. It is important to remember that it is consciousness which directs evolution and spawns physical form. Nature may be defined as the collective unconscious of all the species. Conciousness creates evolution, it is not been lead to believe. We are a consciousness which is both dependent and independent of form and as such we are only temporary either male or female our true identity exists beyond our temporal form. The most important thing which meditation does is to help us to understand our true identity. Yoga gives us power or shakti. 'Shakti' has very much been misunderstood. It is not a mere outer self-assertion, control or power over others. Nor is it mere economic or political dominance. Shakti is the inspiration and joy arising from an inner steadiness, contentment and openness to the flow of Divine grace. Shakti is within us. It holds the essence of all existence at an inner and an outer level. Women especially need to cultivate shakti through meditation to enhance the nurturing and calming nature of the home and the hearth which sustain the family, community and society. The feminine principle must be revered and protected to allow universal healing at a deeper emotional level. Women must be encouraged to cultivate the flow of grace, love and devotion in order to sustain this. Yoga teaches us that spirituality is very much practice in our life.

Meditation brings contentment in our life. To live in content is an art. The more skillfully we lead our lives through the shoals and shallows of life, the happier we shall be and the greater our contribution to the welfare of society. In order to effect wholesome change in our bad inclination and tainted thoughts psychological treatment is what is needed. This bind of treatment is given by yoga in spiritual terminology. By means of practicing meditation and being firmly established in our fundamental and eternal form of self luminous point, we remember the infinite and inexhaustible repository of love, peace, bless and of all divine, virtues who is non other than the supreme soul. Will power is most important power for empowering women and yoga meditation plays an important role in increasing will power of human being. He or she whose will power is week and where mind lacks determination, cannot accomplish any great deed with adequate success. One might today have a good quality and tomorrow it may be lost. Early morning she takes a vow which she breaker before evening comes. She has the wish to be good, but she lacks the ability to fulfill his wish. So, for success in efforts, it is necessary that will power, i.e the quality of determination, should be improved. But, as she has not the power which she needs, she has to get it from someone. And, for one's own good will power can be got from the supreme power because that supreme power (supreme soul) is all powerful. The method of obtaining power from the supreme power is that of yoga which enables us to acquire will power. 
Secondly, when women cannot fulfill her promise she becomes sad and also loses the firm resolve of his thoughts. In this ways of life, there resides the feeling of hopelessness besides complete loss of self-confidence. If instead, she devotes a little time in order firmly to face the strong current of fifthy, she is successful may be to a small extent in the beginning and his earnestness, self confidence and will power will increase so as to enable to met successfully huge difficulties severe criticism and storms of the mind. It is, therefore imperative for women to remember that all the orders, therefore, that come his way are really stepping stones to success and are, therefore fleeing. By going through these or deals we develop in ourselves good qualities and reall greatness. It is universal experience that if the foundations of house are week, the house will not stand for long similarly, if women's thoughts are not firm, her efforts will not continue long. Women specially to practice to firm their thoughts, through practice of yoga. Sri Aurobindo explains the importance of yoga in the following words; (Yoga is) a methodised effort towards self perfection by the expression of the potentialities latend in the being and a union of the human individual with the universal and transcendent existence we see partially expressed in man and in the $\operatorname{cosmos}^{8}$. The synthesis of Yogas (1970) According to Sri Aurabindo, what we need today is the practice of meticulous methods that can bring about redical change of consciousness by means of psychological transmutation of faculties and power of our being. Self reliance points to the basis of our individual outlook, lour social order financial claims, and what is higher that all those, our spiritual views. She who relies upon other to be able to fulfill has needs to protect her, to earn lively -hood for her and to resolve the difficulties which she has to face in everyday life, is considered to be week knead and backward and no better than a handicapped or maimed person. She cannot hold her head heigh. Hence it is no exaggeration to say that dependence upon other in this manner is to accept salvish obedience to them and to hand over the reins of his existence to them. The practice of Niyamas of yoga helps us maintain a positive environment in which to grow, and gives us the self discipline and inner strength necessary to progress in life.

\section{CONCLUSION}

As we know world today is a sea of critical situations, one tougher than the other. It is very true that the present age is the age of problems because as soon as a solution is arrived at, another problem present itself. It is not possible to draw up a list of these problems because now a days we have not but questions and problems at every step. If these are looked into critically and reflected upon, it will be found that body consciousness is at the root of them all. Spirituality teaches us that we are not the body, but a soul. We should realize that we are not black or fair, but it is our skin that is either fair or black. We, who inhabit this frame which wears a skin, are, in fact distinct from the garment we wear. Yoga gives us a devine eye, which enable us to see the gem hidden in the body i.e the soul beneath the skin, which is neither male nor female. Hence every human being has the same potential quality and same every whether it is male or female. In other words soul consciousness is the solution of all kind gender bias in the society.

\section{REFERENCES}

[1]. "Yogini the Enlightent Women" (http://www.vedanet com/Indes. PhP? Option $=$ can - content a task $=$ view id $=55 \mathrm{~d}$ itemid $=2$ http://www.vedant.com/indes php?

[2]. Gates, Janice, Yogini : The power of women, 2006, Mandala Publishing, P-3.

[3]. Dr. Swami Shankardevanda Sarawati. The importance of Shakti, Yoga Magazine, May 1999, London England.

[4]. K.Gill, Hindu women's property in India, New Delhi; Deep and Deep publications 1986) P 17.

[5]. As quoted by A.S Altekar, The position of women in Hindu Civlilzation (Delhi Motilal Banarasidass $2^{\text {nd }}$ edn 1983) P.316.

[6]. M.Cormack, She who rides a peacock. Indian student and social change (Bombay Asia Publishing House, 1961) P.104.

[7]. N Gorway, Self Image and Social Change : A study of Female students (New Delhi, sterling publisher) P.2. 